Sustinere

Journal of Environment and Sustainability

Volume 1 Issue 1 (2017) 23-36

Print ISSN: 2549-1245 Online ISSN: 2549-1253

Website: https://sustinerejes.com E-mail: sustinere.jes@iain-surakarta.ac.id

\title{
RESEARCH PAPER \\ The characterization of tourmaline and its effects on plant growth
}

\author{
Sin-Yi Huang1, Chun Ming Yu 2, Po-Yuan Liu 2, Yun-Hseng Yu ${ }^{2}$, \\ Chien Hung Chen ${ }^{3}$, Ching Fung Liư ${ }^{4}$, Yaju Juang3,* \\ ${ }_{1}^{1}$ Institute of Environmental Engineering, National Chiao Tung University, Hsinchu City, Taiwan \\ ${ }^{2}$ Artcera Co., Ltd., Taoyuan City, Taiwan \\ ${ }^{3}$ Material and Chemical Research Laboratories, Industrial Technology Research Institute, Hsinchu City, \\ Taiwan \\ ${ }^{4}$ Dept. of Chemical Engineering, National Tsing Hua University, Hsinchu City, Taiwan
}

Article history:

Received 01 December 2016 | Accepted 03 April 2017 | Available online 25 July 2017

\begin{abstract}
The purpose of this study was to investigate the characteristics of ACERALIVEN $^{\mathrm{T}}$, a commercial tourmaline, and to test its effect on plant growth. According to our analysis, ACERALIVEN ${ }^{\mathrm{m}}$ belongs to the Si-Al-Mg tourmaline structure. It contains some trace metals such as zirconium, potassium, and iron and able to emit far-infrared energy in the emissivity of 0.829. Introducing the tourmaline into water changes the water to be more alkaline. Tourmaline also releases negative hydroxyl ions and dissolved oxygen creating what is called as hydrogen water. Mung beans submerged with ACERALIVEN ${ }^{\mathrm{m} m}$ shows a longer lifetime than without submerging the tourmaline. Additionally, the tourmaline can promote plant growth by removing chlorine and releasing far-infrared which is beneficial for plant's metabolism.
\end{abstract}

Keywords: ACERALIVEN ${ }^{\mathrm{TM}}$, far-infrared material, plant growth, tourmaline

\section{Introduction}

Tourmaline is one of the earliest natural minerals discovered having piezoelectric and thermoelectric characteristics (Han \& Liang, 2009). In the early $18^{\text {th }}$ century, the Dutch bring a tourmaline from Ceylon, India to Europe. The tourmaline, also called Ceylon magnetic, was found to have the adsorption of coal ash when it is heated. In 1880, another name for the piezoelectricity of the tourmaline was also published by Jacques and Pierre (Draper, 1861) due to its piezoelectric properties (Erhart $t$ al., 2010). Tourmaline is a complex silicate mineral groups. Mostly, it is a complex silicate of aluminum or other elements entering into the structure, such as sodium, calcium, iron, magnesium and lithium Song \& kang, 2008). 
Some recent studies indicate that the unique chemical structure of tourmaline results in many valuable properties such as the ability to generate the negative hydroxyl ions, produce electrostatic field, release rare microelements, stimulate the growth and metabolism of microorganisms, adsorb metals from the aquatic environment and also the ability to radiate far-infrared energy (Wang et l., 2012; Wang et al., 2011; Xia et al., 2006). It was also pointed out that $\mathrm{OH}^{-}$produced by tourmaline combine with oxygen molecules in the water will produce $\mathrm{H}_{3} \mathrm{O}_{2}$ - This ion has reducing capability and reacts with oxidants such as hypochlorous acid which in turn eliminate residual chlorine in the water. The negative hydroxyl ion released by tourmaline can olso neutralize free radicals and reduce its harmfulness. Moreover, the release of far-infrared and negative hydroxyl ions promotes growth and anti-aging for plants (Han \& Liang, 2009; Ni et al., 2008; Shen et al., 2015). Lee, et al. (2006) used far-infrared to irradiate peanut shells for 5 to 60 minutes and found that the phenolic compound and free radical scavenging activity increased significantly. Many literatures have proved tourmaline shows a potential to alter water quality and enhance plant growth. Unfortunately, little research have discussed the potential of harnessing far-infrared radiation from tourmaline for improving plant growth.

In this study, the commercial tourmaline (ACERALIVEN ${ }^{\mathrm{m}}$ ) was thoroughly analyzed to obtain a complete knowledge on its characteristics and the ability to transfrom water quility. Subsequentsly, its application into plant growth media was experimented to investigate its effect on plant growth.

\section{Material and method}

\subsection{Material}

ACERALIVEN $^{\text {mm }}$ (Figure 1) was purchased from Artcera Co., Ltd., Taiwan (Patent No.: US 6548118 B1 and TW 163394). The effects of tourmaline on the plant growth were carried out using mung beans (Vigna radiata) grown in a hydroponic media. The mung beans growth was recorded with a camera.

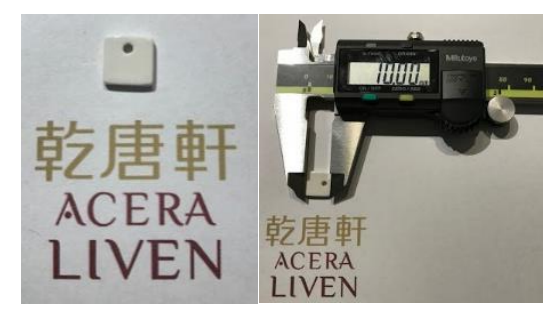

(a)

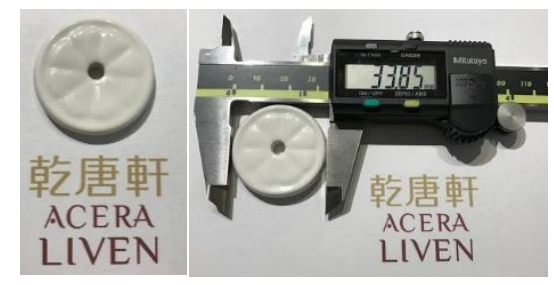

(b)

Figure 1. ACERALIVEN $^{\mathrm{m}}$ (a) square-shaped, $10.00 \mathrm{~mm}$; (b) round-shaped, $33.85 \mathrm{~mm}$ 


\subsection{Analysis of tourmaline \\ Composition of element}

The XPS measurement used in this work is ULVAC-PHI XPS. The powder of ACERALIVEN $^{\text {mm }}$ was compressed tablet and its chemical component and composition were analyzed. It operates at a base pressure below $5 \times 10^{-10}$ torr. The X-ray system was water cooled with $\mathrm{Al}$ anode operated at a voltage of $10 \mathrm{kV}$ and an emission current of $40 \mathrm{~mA}$, this gave a working power of $400 \mathrm{~W}$. The spectra were analyzed using the COMPASS software. Peaks were generally fitted using a Gaussian-Lorentzian peak shape with a Shirley-type background. Carbon element was used as background; the energy position of XPS lines needed to shift corresponds to the calibration.

\section{Analysis of surface morphology}

SEM images in this work were obtained with a Hitachi SU8010, which used a tungsten filament as electron source and there was a camera for capturing digital micrographs of the specimen. The nominal resolution was $10 \AA$ (at $15 \mathrm{kV}$ ), accelerating voltage was 0.1 to $30 \mathrm{kV}$, and magnification was up to $8000,000 \times$. The SEM was equipped with energydispersive $\mathrm{x}$-ray spectroscopy (EDS) and can be used to identify non-trace elements $(\mathrm{Z}>3$ ) in the samples. The powder of ACERALIVEN ${ }^{\mathrm{m}}$ was fixed on the carrier and for insulating the samples gold coating is required.

\section{Far-infrared emissivity}

The emissivity of infrared radiation was measured via VERTEX 70 FT-IR Spectrometer (Bruker Optik $\mathrm{GmpH}$ ) at $25^{\circ} \mathrm{C}$ of room temperature and $60 \% \mathrm{RH}$. Molecules maintain vibration or rotation; it can transit to the excited state while the molecules absorb the appropriate frequency of infrared. The infrared detection is a non-destructive analysis, it will not damage the molecular structure. The energy of infrared measures at 40 to $90{ }^{\circ} \mathrm{C}$ and the wavelength of 4 to $14 \mu \mathrm{m}$. The far-infrared emissivity is the ratio of infrared energy to blackbody emission.

\section{Energy band}

The energy band is based on the photoelectric effect by analyzing the transmittance and reflectance using UV/VIS spectrometers. The ACERALIVEN ${ }^{\mathrm{m}}$ powder's wavelength was detected from 200 to $900 \mathrm{~nm}$. Energy band was expressed relation:

$$
\mathrm{E}_{\mathrm{g}}=1240 / \lambda_{\text {onset }}
$$

\section{Composition of metal ions}

The composition of metal ions was determined by the inductively coupled plasma/optical emission spectrometers (700 Series ICP/OES, Agilent Technology). The metal and nonmetallic substances of the materials are pretreated by a strong acid digestion. The powder of ACERALIVEN ${ }^{\mathrm{Tw}}$ was digested by adding $2 \mathrm{~mL} 8 \mathrm{M} \mathrm{HNO}_{3}$ and $1 \mathrm{~mL}$ $6 \mathrm{M} \mathrm{HCl}$ into $100 \mathrm{~mL}$ sample. Temperature was controlled at $85{ }^{\circ} \mathrm{C}$ and refluxed for 4 hours. Then it was diluted to $50 \mathrm{~mL}$ and filtrated by $0.45 \mu \mathrm{m}$ membrane. 


\section{Measurement of negative hydroxyl ions}

Measurements of negative hydroxyl ions were conducted with Lutron NI-214 negative hydroxyl ions tester. The amount of negative hydroxyl ions and the strength of alkaline water are detected by the reduction potential $(\mathrm{mV})$ of the water.

\section{Electrochemical properties}

Electrochemical measurements were conducted with a $\mathrm{CH}$ Instruments 4053a potentiostat. The Pt wire $\left(3.16 \mathrm{~cm}^{2}\right)$ and Pt sheet $\left(4 \mathrm{~cm}^{2}\right)$ were used as the working and counter electrodes, respectively. The reference electrode was used the $\mathrm{Ag} / \mathrm{AgCl}$. The electrochemical measurements along with cyclic voltammetry (CV) were carried out with potentiostat interfaced with a computer. The potential range was -0.1 to $1.4 \mathrm{~V}$ vs. RHE at a scan rate of $10 \mathrm{mV} / \mathrm{s}$. Open-circuit potential (OCP) versus time was recorded in agreement with the CHI 4053a. The OCP was measured for 20 min while the tourmaline (Figure 1 (a)) was submerged into the DI water.

\subsection{Plants growth studies}

The effects of tourmaline on the plant growth were carried out with hydroponics method. The mung bean was chosen as the investigational plant and reverse osmosis (RO) water, such as drinking water, was used as the growth media. The experimental group contained tourmaline (Figure 1 (b)) in the growth media while control group was without tourmaline. The mung beans growth was recorded with a camera, and its height was measured over time.

\section{Results and discussion}

\subsection{Characteristic of ACERALIVEN ${ }^{\mathrm{m}}$}

Tourmaline mainly contains cyclosilicate phase, exhibiting a defect properties due to their piezoelectric structures which composed of transition elements (Lee et al., 2006; Hawthorne \& Henry, 1999; Henry et al., 2011). These characteristics caused the permanent polarization effect as well as the transition of electrons to produce $0.6 \mathrm{~mA}$ of current and thus generate negative hydroxyl ions and far-infrared. Figure 2 shows the SEM images of its morphology and elements composition. The particle size is about 1 10 $\mu \mathrm{m}$, and the EDS analysis shows that its composition varies widely of oxygen, silicon, aluminum, carbon and other elements, including zirconium, potassium, and iron. The $\mathrm{Mg}$ signal located at approximately 1.2-1.3 kev cannot be obviously detected on the surface of tourmaline. Therefore, the ICP-OES were also applied for measuring the total metal ions in tourmaline.

Table 1 lists the dissolved metal ions of tourmaline detected by ICP-OES. It shows that aluminum, silica, calcium, and magnesium were the major components; the concentrations are larger than $1 \mathrm{mg} / \mathrm{g}$. According to tourmaline ternary phase diagrams (Spicer, 2004), most of the tourmaline was composed of $\mathrm{Al}, \mathrm{Fe}, \mathrm{Mg}$ and others. Different structures of tourmaline will be produced by different proportions of elements. The ACERALIVEN ${ }^{\mathrm{m}}$ which was used in this study belongs to the Si-Al-Mg tourmaline structure. These transition metals in the crystal structure can easily promote the electron transition (Hsieh et al., 2007) and emit the far-infrared of the wavelength range from 3 to $1000 \mu \mathrm{m}$. It has been proved that the infrared radiation from tourmaline improve the circulation in the 
human body, diminish inflammation, and inhibit cancer, as well as optimizing combustion efficiency, uniformity of temperature distribution, heat transfer performance, heating efficiency, and chemical reactions; lead to its wide application in the medical and engineering field (Hsieh et al., 2007 \& Hsu \& Teng, 2016).

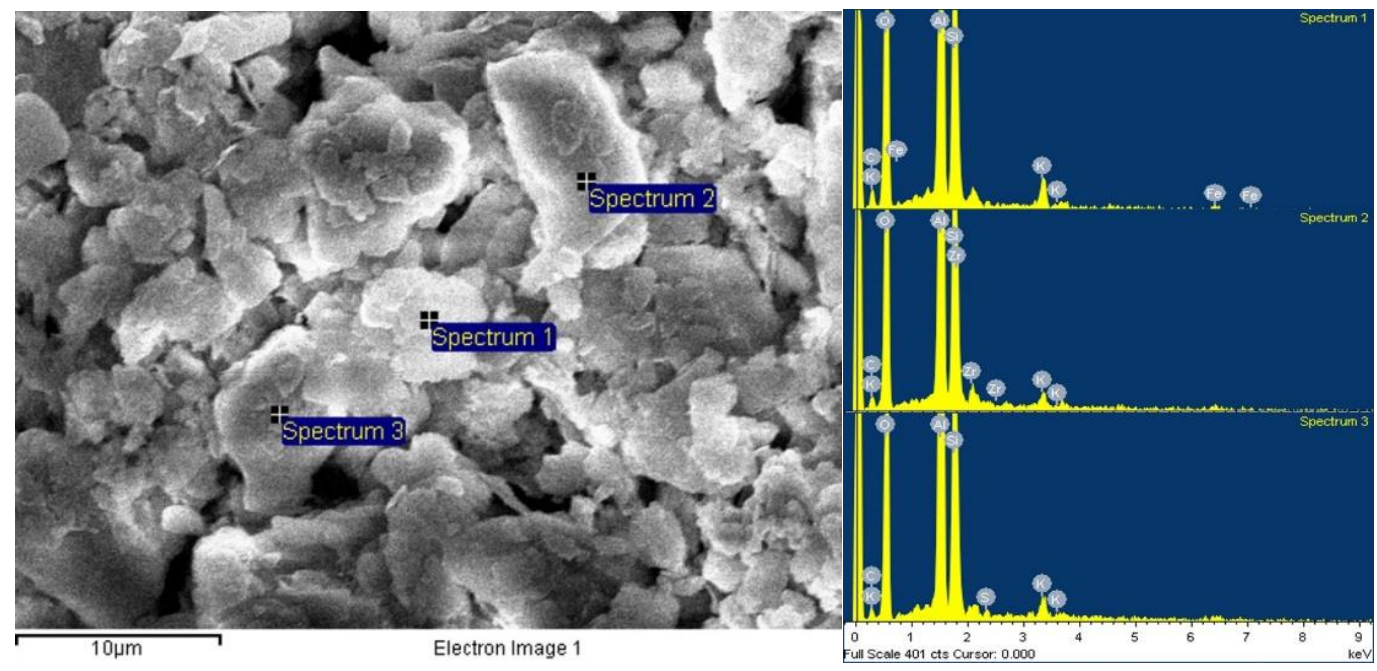

Figure 2. The morphology of tourmaline and element composition

Table 1. The composition of metal ions

\begin{tabular}{cccccccccccc}
\hline Element & $\mathrm{Al}$ & $\mathrm{Si}$ & $\mathrm{Ca}$ & $\mathrm{Mg}$ & $\mathrm{B}$ & $\mathrm{Cr}$ & $\mathrm{Mn}$ & $\mathrm{Ni}$ & $\mathrm{Pb}$ & $\mathrm{Zn}$ & $\mathrm{Cu}$ \\
Conc.(mg/g) & 137.7 & 1.84 & 10.6 & 1.21 & 0.06 & 0.06 & 0.98 & 0.1 & 0.04 & 0.28 & 0.05 \\
\hline
\end{tabular}

The full spectrum of XPS (Figure 3) shows that the main compositions are $\mathrm{Si}, \mathrm{Al}$, and 0 . The peak of 01 s could be divided into two characteristic peaks, one was Al-O at 531.2 $\mathrm{eV}$ (Choi et al., 2010) and another was Si-O at $532.1 \mathrm{eV}$ (Wang et al., 2006). The peak of Al $2 \mathrm{p}$ at $74.5 \mathrm{eV}$ represent $\mathrm{Al}_{2} \mathrm{O}_{3}$. The $\mathrm{Si} 2 \mathrm{p}$ spectrum in which two peaks were observed at $102.2 \mathrm{eV}$ and $102.7 \mathrm{eV}$ can be attributed to the silicones $\left(-\mathrm{R}_{2} \mathrm{SiO}-\right)$ and silicates $\left(\mathrm{SiO}_{2}\right)$, respectively (Song \& Kang, 2008). However, the tourmaline was dominantly composed of $\mathrm{Al}_{2} \mathrm{O}_{3}$ and $\mathrm{SiO}_{2}$.

The energy band was analyzed by UV-Vis in the full wavelength range from $200 \mathrm{~nm}$ to $900 \mathrm{~nm}$, and the results are shown in Figure 4. The absorptions for $\mathrm{Si}$ and $\mathrm{Al}$ were observed at $609 \mathrm{~nm}$ and $406 \mathrm{~nm}$, which can be converted to energy band by the modified Kubelka-Munk equation to $2.03 \mathrm{eV}$ and $3.05 \mathrm{eV}$, respectively. In the literature, energy band of $\mathrm{Si}$ and $\mathrm{Al}$ were around 1.11-1.12 eV (Low et al., 2008) and 3.54-3.64 eV, respectively. Thus, the energy band of Si and Al here were obviously shifted. This could be because the ACERALIVEN $^{\text {m }}$ with the function of photocatalysis, contains transition metals, which led to the crystal defects. This result can also verify that ACERALIVEN ${ }^{\mathrm{mm}}$ mainly composed of $\mathrm{SiO}_{2}$ and $\mathrm{Al}_{2} \mathrm{O}_{3}$, producing the energy band at $2.03 \mathrm{eV}$ and $3.05 \mathrm{eV}$, respectively, and that the tourmaline would release the far-infrared due to its lattice defect structure, as described in the literature (Hsieh et al., 2007). 


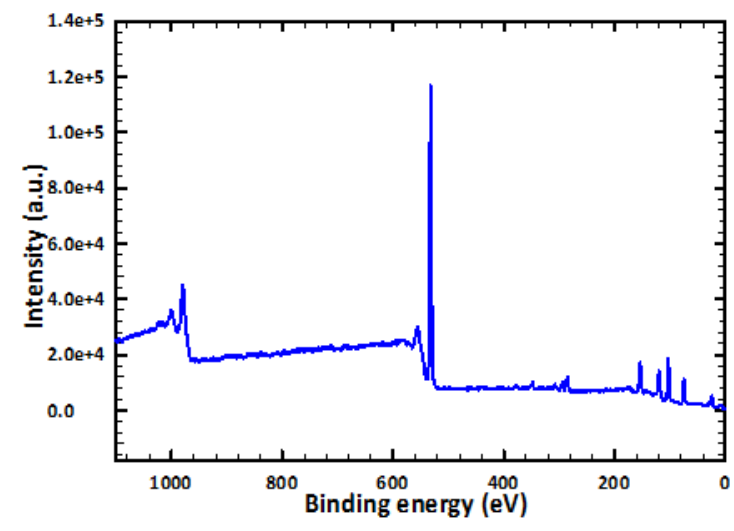

(a)

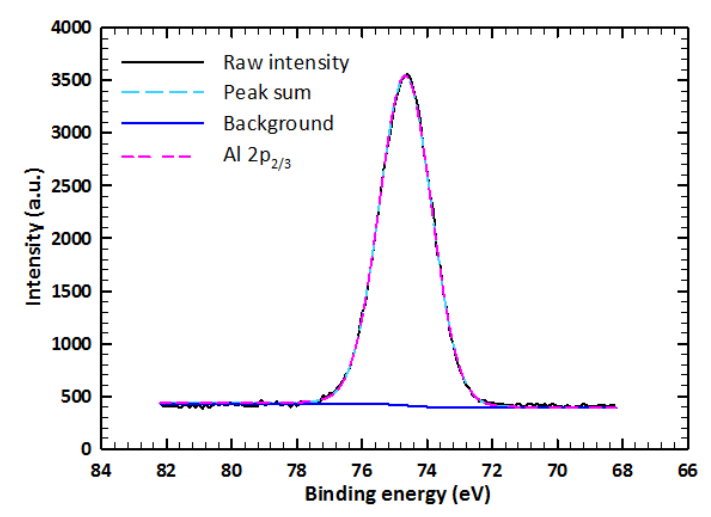

(c)

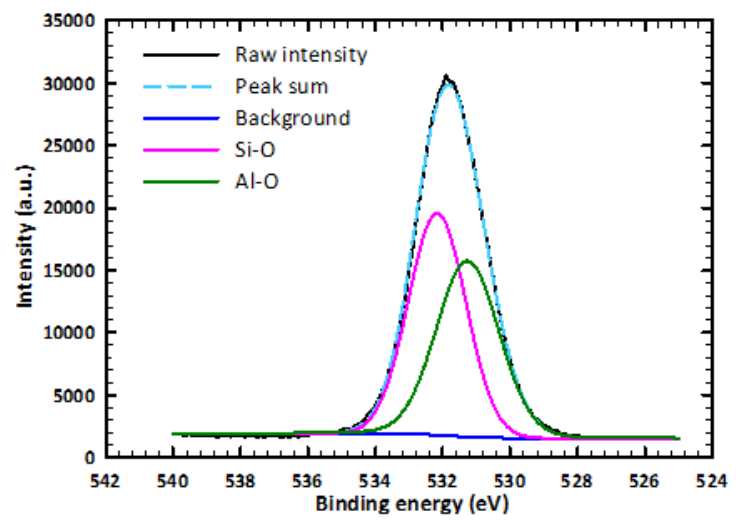

(b)

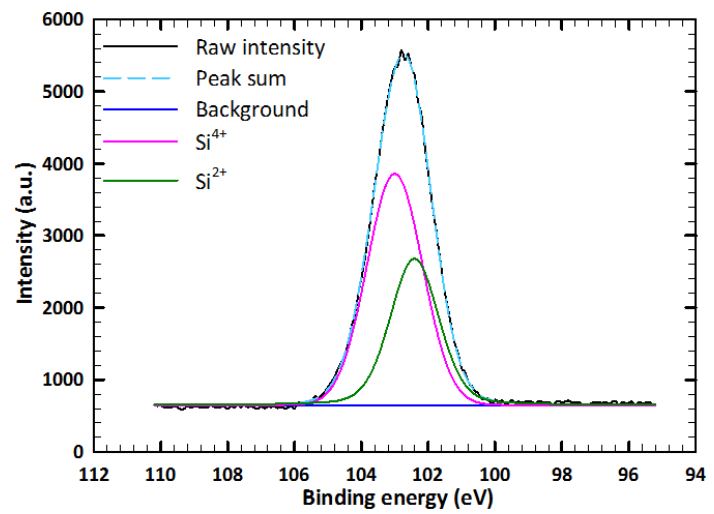

(d)

Figure 3. The XPS analysis of (a) full spectrum, (b) 0 1s (c) Al 2p; (d) Si 2p
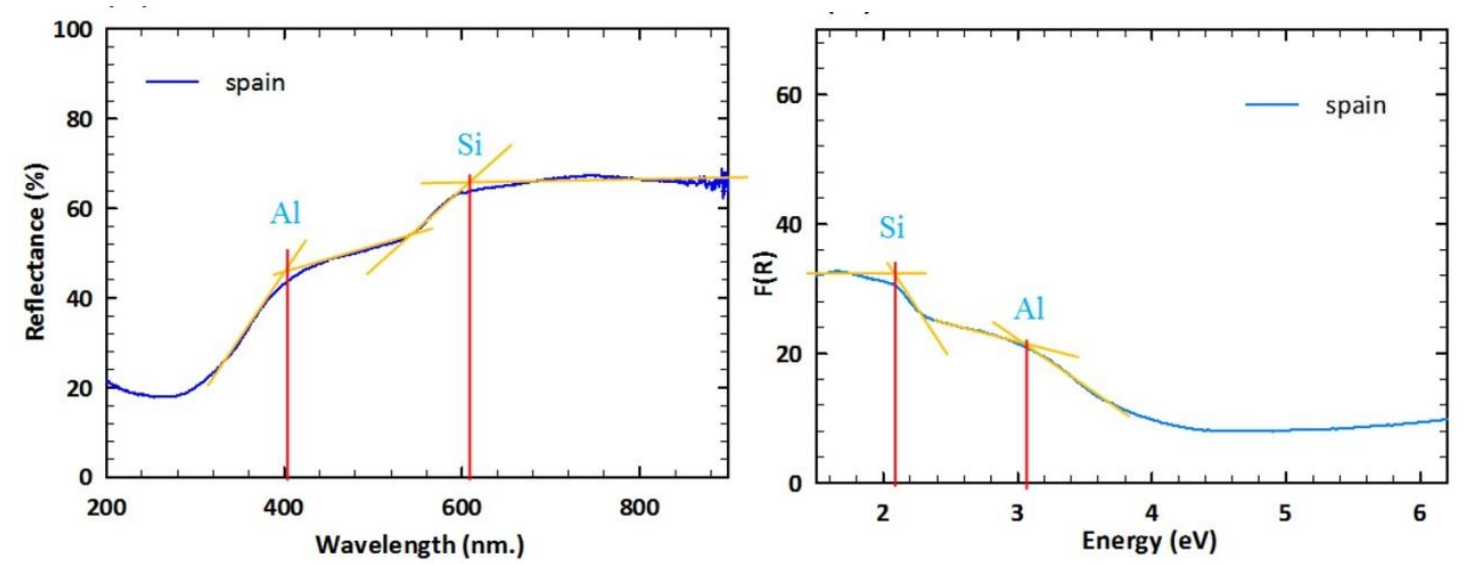

Figure 4. The UV-Vis spectrum of ACERALIVEN ${ }^{\mathrm{m}}$, based on (a) wavelength (b) energy band 


\subsection{Effects of tourmaline on water quality}

Based on the above results of material properties, ACERALIVEN ${ }^{m}$ has proven to have the characteristics of radiating far-infrared. Here, the effects of ACERALIVEN ${ }^{m}$ on the quality of water into which it was submerged, was tested. The parameter measured were $\mathrm{pH}$, negative hydroxyl ions concentration, oxidation-reduction potential (ORP), conductivity, and dissolved oxygen (DO) as shown in Table 2. The pH of deionized water (DIW) was increased as a function of time and was biased towards neutral. For the drinking water (DW), it was insignificantly changed and remained neutral. The negative hydroxyl ions in drinking water were significantly increased, but it was decreased in the deionized water. According to the literature, it indicates that the negative hydroxyl ions were contributed by the combination between $\mathrm{OH}^{-}$and $\mathrm{H}_{2} \mathrm{O}$ (Wang \& $\mathrm{Li}, 2010$ ). Therefore, the concentration of $\mathrm{OH}^{-}$in deionized water was lower than drinking water, resulted in a small number of negative hydroxyl ions.

Table 2. Water properties after the introduction of ACERALIVEN ${ }^{\mathrm{rm}}$

\begin{tabular}{ccccccccccc}
\hline \multirow{2}{*}{ Min } & \multicolumn{3}{c}{$\mathrm{pH}$} & \multicolumn{3}{c}{$\begin{array}{c}\text { Negative } \\
\text { ion(mV) }\end{array}$} & \multicolumn{2}{c}{ ORP(mV) } & Conductivity $(\mu \mathrm{S})$ & \multicolumn{2}{c}{ DO (mg/L) } \\
\cline { 2 - 10 } & DIW & DW & DIW & DW & DIW & DW & DIW & DW & DIW & DW \\
\hline 0 & 5.58 & 7.11 & 329 & 237 & 91 & 5 & 22.7 & 20.9 & 5.7 & 5.2 \\
10 & 6.11 & 7.12 & 273 & 273 & 61 & 4 & 33.0 & 32.9 & - & 5.4 \\
20 & 6.14 & 7.22 & 294 & 291 & 59 & -1 & 86.4 & 45.6 & - & 6.5 \\
30 & 6.15 & 7.28 & 280 & 293 & 59 & -5 & 97.4 & 56.2 & - & 7.3 \\
40 & 6.16 & 7.32 & 268 & 287 & 58 & -7 & 108.4 & 66.8 & - & 8 \\
\hline
\end{tabular}

DIW: Deionized water; DW: Drinking water made from Reverse osmosis (R0) filtration

To confirm the elimination of residual chlorine from water by ACERALIVEN ${ }^{m}$, it was submerged into the water with various concentration of residual chlorine. Figure 5 shows that the concentration of residual chlorine in the tap water was decreased from $0.12 \mathrm{mg} / \mathrm{L}$ to $0.04 \mathrm{mg} / \mathrm{L}$ after ACERALIVEN ${ }^{\mathrm{m}}$ was submerged for 10 mins. The hypochlorous acid can be reduced to chloride by the negative hydroxyl ions, a reducing agent capable of free radical neutralization, provide beneficial anti-aging effect, and metabolism and cell activation.

The oxidation reduction potential (ORP) is a measurement of the redox capacity of aqueous solution. The water is oxidant when the ORP is positive. By contrast, negative ORP represents that water is as a reducing agent or antioxidant. In this condition, water generally refers to as "negative potential" or "negative potential water" and also called as "reduced water" or "hydrogen water". The ORP of both deionized water and drinking water were significantly decreased, indicates that the increasing negative hydroxyl ions would result in the water to shift towards reduced water. Moreover, the increasing conductivity in the water indicated that the ions number were significantly increased in the water. This condition is beneficial to balance the lactic acid and peroxide radicals produced by the metabolic processes, and to remove harmful substances, such as chlorides, chromates, nitrites and heavy metals. Thus, negative potential water has several beneficial effects. 


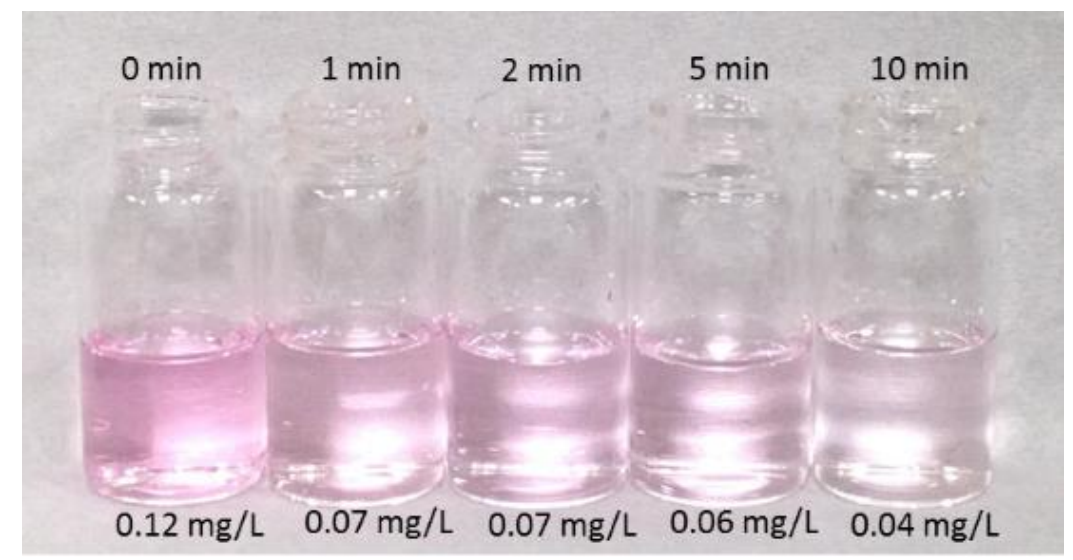

Figure 5. The residual chlorine in water versus times

To verify the increasing negative hydroxyl ions and $\mathrm{pH}$ caused by tourmaline, the electrochemical method was used to analyze the formation of negative ions in water by tourmaline. Figure 6 (a) shows the open-circuit potential measured at a Pt wire electrode when exposed to deionized water. The main composition of ACERALIVEN ${ }^{\mathrm{m}}$ from Table 1 is similar to Kaolin $\left(\mathrm{Al}_{2} \mathrm{Si}_{2} \mathrm{O}_{5}(\mathrm{OH})_{4}\right)$; therefore, these two materials were applied to understand the effects of ACERALIVEN ${ }^{\mathrm{m}}$, which contains other elements such as zirconium, potassium, and iron, on the quality of water. To compare with a similar material to understand the effects of the functional ACERALIVEN ${ }^{\mathrm{m}}$, kaolin (A Type, Figure 6), which composition is $\mathrm{Al}_{2} \mathrm{Si}_{2} \mathrm{O}_{5}(\mathrm{OH})_{4}$, and ACERALIVEN ${ }^{\mathrm{m}}$ (B Type, Figure 6) were submerged into deionized water during the measurement. As can be seen, the slope of open circuit potential from B type was larger than the blank (without submerged-tourmaline) and A type during the 20 mins submerging. The measured open-circuit potential decreased as a function of submerging time. It can be proposed that the formation of negative hydroxyl ions by ACERALIVEN ${ }^{\mathrm{m}}$ resulted in the increase of the concentration of negative hydroxyl ions in deionized water. When the open-circuit potential measured at a Pt wire electrode exposed to tap water, as shown in Figure 6 (b), it can be clearly observed that the B type (with ACERALIVEN ${ }^{m}$ ) shows the decreasing curve compared to the blank and A type. Therefore, the charge of the Pt surface would become negative, corresponding to Table 2. Based on this result, it is confirmed that the ACERALIVEN ${ }^{\mathrm{m} m}$ has the ability of self-discharge, to this point it could radiate far-infrared.

To have further insight on the relationship between the ionic strength and formation of negative ions by submerged-ACERALIVEN ${ }^{\mathrm{rm}}$, the cyclic voltammetry analysis is employed to detect the oxygen reduction reaction as well as the hydrogen adsorption and desorption behavior on a Pt electrode. For the typical shape of Pt CV curve, the positive sweep shows the oxidation of underpotential deposition (UPD) hydrogen atoms (0-0.4 V), double-layer process (0.4-0.8 V), and oxy-hydroxide formation region ( $>0.8 \mathrm{~V}$ ) although minor anodic currents due to Pt adatom oxidation are observed at $0.68 \pm 0.05 \mathrm{~V}$ (Daubinger et al., 2014). On the following negative sweep, cathodic currents commence at $1.4 \mathrm{~V}$ and the large reduction peak centered at $0.7 \mathrm{~V}$ is due to the reduction of platinum oxy-hydroxide formed on the positive sweep at potentials positive to $0.8 \mathrm{~V}$. Then, UPD 
hydrogen commences at potentials negative to $0.4 \mathrm{~V}$, which is highly reversible from the symmetric adsorption and desorption peaks (Daubinger et al., 2014).
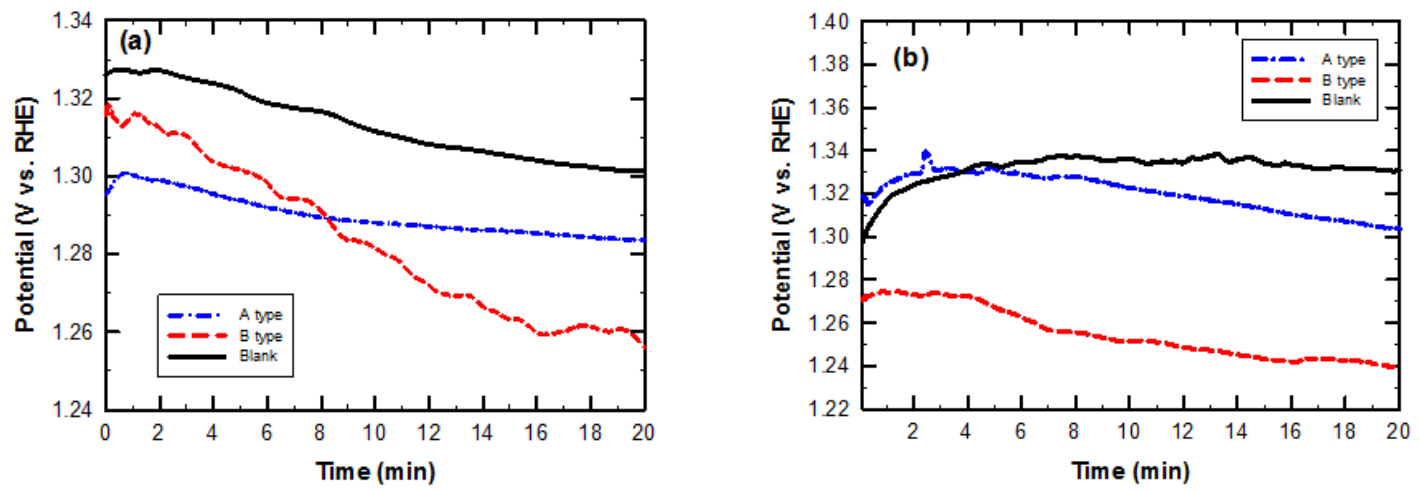

Figure 6. Open-circuit potential measured as a function time using a Pt wire electrode. Kaolin (Type A) and commercial tourmaline (Type B) were submerged (a) in deionized water and (b) in tap water without nitrogen purging.

Figure 7 shows a cyclic voltammogram of a platinum measured in deionized water. From the blank and A type curve, the peak of adsorption and desorption of hydrogen atoms were observed, however, the shape of the curves were different to the shape of "stabilized" platinum metal (Daubinger et al., 2014) due to the concentration of the ions in deionized water were quite low and could not provide enough ions to sense the electrochemical reaction on the Pt surface. The curve of B type is slightly similar in shape to that of the "stabilized" platinum metal. It could be suggested that the formation of ions occurred and that the conductivity was increased which promoted the sensitivity of electrochemical analysis during the CV test. It proves that the ACERALIVEN ${ }^{m}$ with farinfrared excitation changed the water quality.

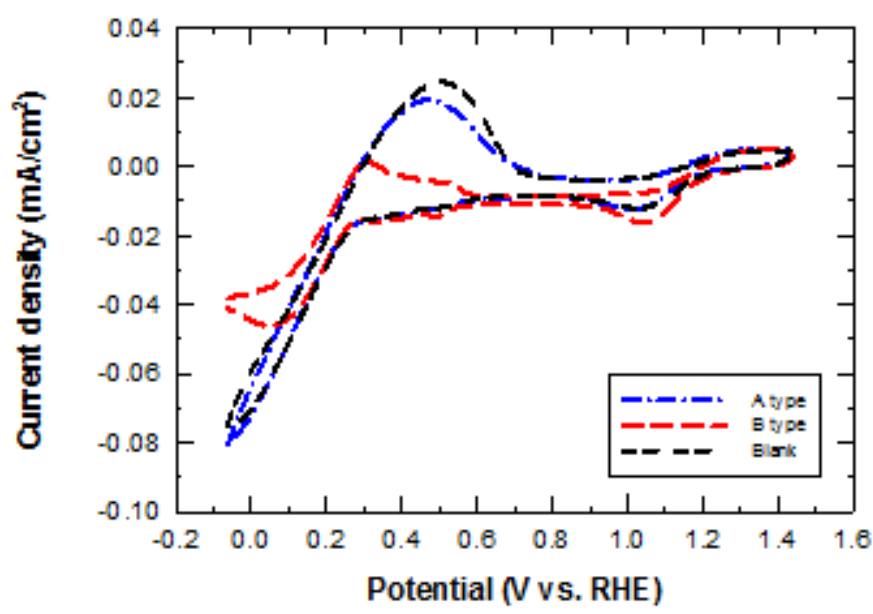

Figure 7. Cyclic voltammograms of a Pt electrode measured in DI water with Kaolin (A type), with commercial tourmaline (B type), and blank (scan between -0.1 and $1.4 \mathrm{~V}$ at $10 \mathrm{mV} / \mathrm{s}$, without nitrogen purging) 
Furthermore, CV was measured at the deionized water and tap water (Figure 8). The shape of the curve of tap water (Figure 8 (a)) is more similar to the typical cyclic voltammogram of "stabilized" platinum metal. It means the tap water shows improved response due to the higher ionic content, providing conductivity in water, compared to deionized water. Figure 8 (b) shows the Pt electrode measured at tap water with a different type of submerged materials. It was no significant changes between the shapes of curves due to the high ionic strength in tap water compared to the normal electrolyte. This high ionic strength caused no obvious effect of ACERALIVEN ${ }^{\text {tm }}$ in the tap water.
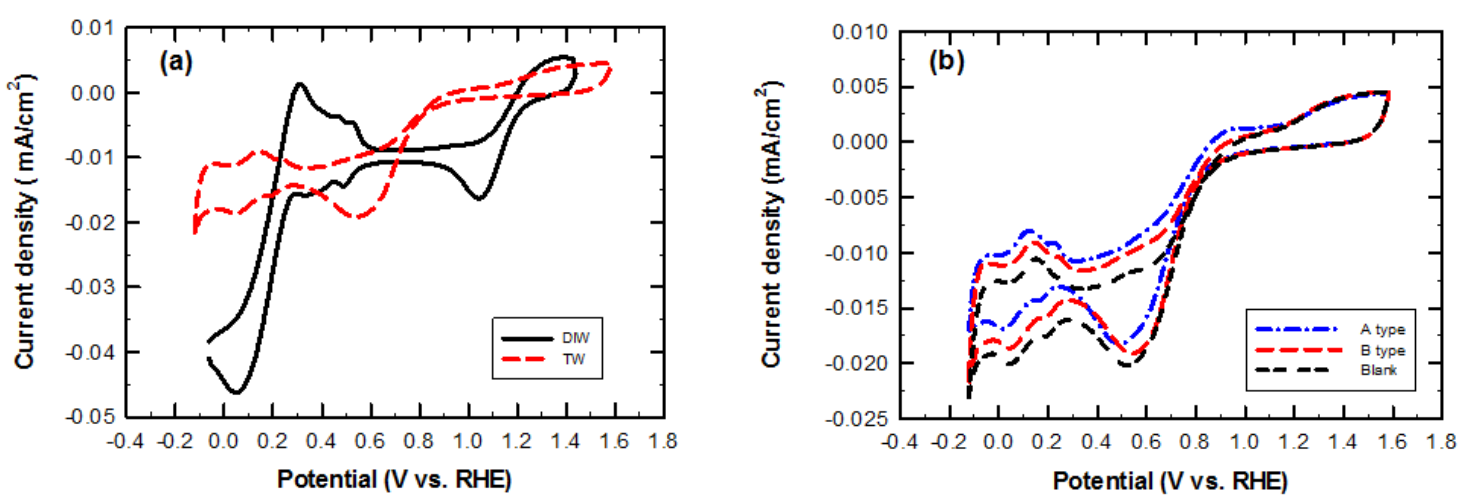

Figure 8. Cyclic voltammograms of a Pt electrode measured between -0.1 and $1.6 \mathrm{~V}$ at $10 \mathrm{mV} / \mathrm{s} \mathrm{(a)} \mathrm{in} \mathrm{deionized} \mathrm{water} \mathrm{(DIW)} \mathrm{and} \mathrm{tap} \mathrm{water} \mathrm{(TW)} \mathrm{with} \mathrm{tourmaline;}$ (b) in tap water with kaolin (A type), tourmaline (B type), and without tourmaline (blank). The measurements were without nitrogen purging.

\subsection{Effect of ACERALIVEN ${ }^{\mathrm{m}}$ on the plant growth}

There is various application of far-infrared in medical research and treatment; however, for its effect on plant growth only little research could be found. In this work, the daylight effects of tourmaline on the plant growth were carried out using mung beans grown hydroponically using RO water and fluorescent lamp. Experimental group contained ACERALIVEN ${ }^{\mathrm{m}}$ (right-hand side) and the control group was without tourmaline (left-hand side) as shown in Figure 9. When it was on the third-sixth day (a-b), it was observed that the germination of mung bean in the experimental group was faster than the control group. After $8^{\text {th }}$ day (c-f) the plant height and relative growth rate of mung bean with far-infrared tourmaline were significantly taller than the control group. Moreover, the color of the leaf was green and lustrous due to the emission of far-infrared energy from tourmaline can promote dark green leaves (Chen et al., 2010). However, it was found that the leaves couldn't grow until $14^{\text {th }}(\mathrm{g}-\mathrm{h})$ in the control group, in contrast with the experimental group. These results showed that the antioxidant ability of the plant could be enhanced by far-infrared irradiation (Jin et al., 2013) resulted by ACERALIVEN ${ }^{\mathrm{m}}$. 

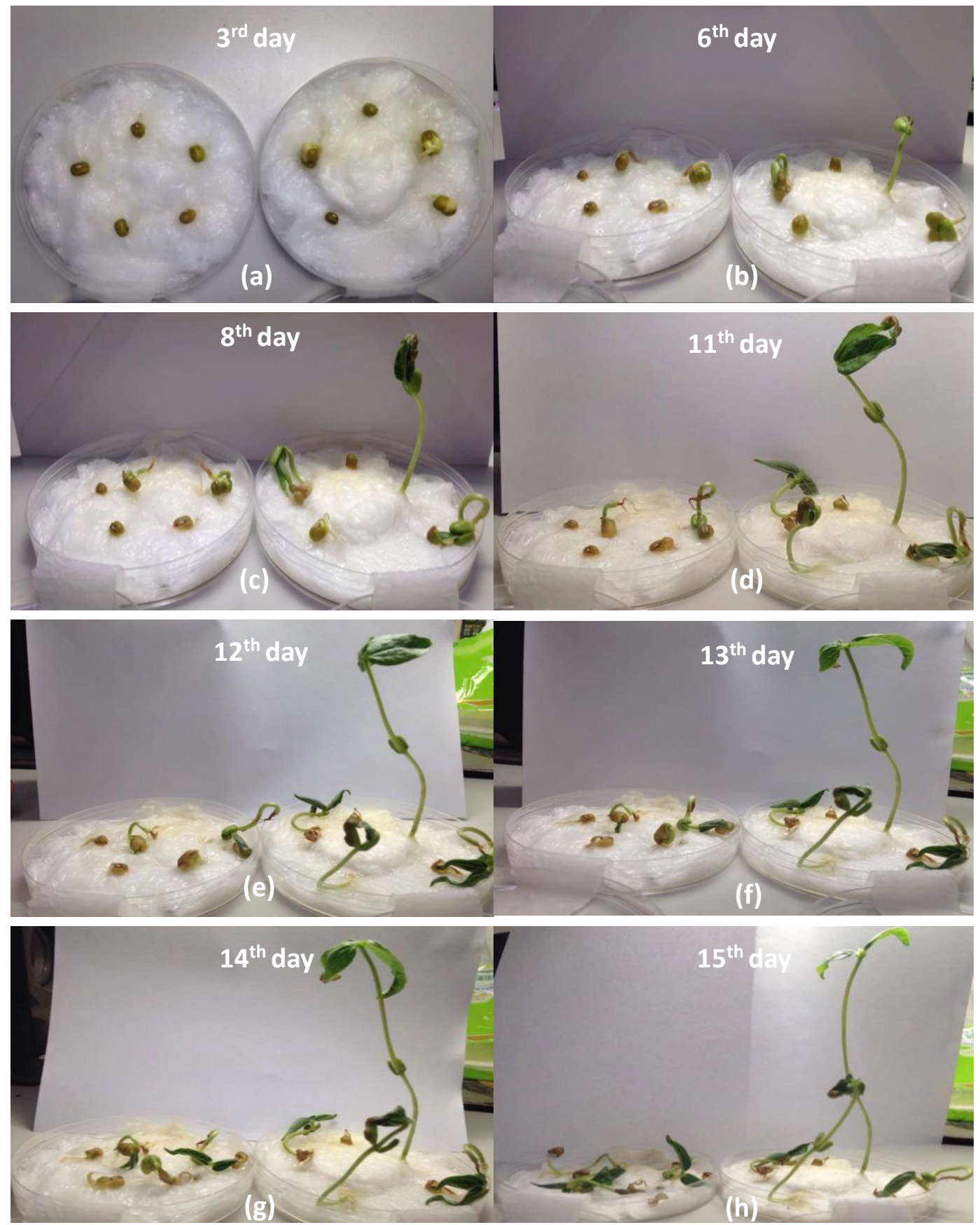

Figure 9. The daylight effects of tourmaline on the plant growth, control group was without tourmaline (left side) and experimental group was with tourmaline (right side)

\section{Conclusions}

In addition to analyzing the basic characteristics of ACERALIVEN ${ }^{\mathrm{m}}$, the purpose of this study was to explore its application to stimulate plant growth. The following conclusions are drawn based on the result of the study. 
According to the results of elemental analysis, it was found that the ACERALIVEN ${ }^{\text {m }}$ belongs to the Si-Al-Mg tourmaline structure. The transition metals contained caused the crystal structure to easily promote the electron transition and far-infrared emission. UVVis analysis indicated that ACERALIVEN ${ }^{m}$ produced energy band at $2.03 \mathrm{eV}$ and $3.05 \mathrm{eV}$, confirming that it mainly composed of $\mathrm{SiO}_{2}$ and $\mathrm{Al}_{2} \mathrm{O}_{3}$. In the electrochemical analysis, the OCP measured in solution with submerged-ACERALIVEN ${ }^{m}$ decreased with the time. It showed that the charge on the electrode surface was neutralized due to the increasing negative hydroxyl ions and the $\mathrm{pH}$ caused by ACERALIVEN ${ }^{\mathrm{m}}$. The electrochemical behavior of oxygen and hydrogen in the water could be confirmed by the CV curve. The ACERALIVEN $^{\mathrm{m}}$-containing water had a significant reaction, because of the increasing conductivity caused by negative hydroxyl ions released. The ACERALIVEN ${ }^{\mathrm{m}}$ could change the water to negative ion water (reduced water) and eliminate residual chlorine, hence promotes metabolism and activates cells. In the mung bean growth test, the ACERALIVEN ${ }^{\mathrm{m}}$ maintained the growth of the plant several days longer. It indicates that the far-infrared emitted by ACERALIVEN ${ }^{m}$ provide better growth conditions and the antioxidant ability to the plant.

\section{Acknowledgement}

We acknowledge all the volunteers of this study for their willingness and diligence in complying this paper. We also thank Ervin Nurhayati of Department of Environmental Engineering, Institut Teknologi Sepuluh Nopember, Surabaya, for overseeing the conduct of this study. This study was supported by Artcera Co., Ltd., Taiwan.

\section{References}

Chen, C.L., Chen, C.C., Ai, K., Liao, J.H., Chen, P.C. (2010) "The characterization and planting application of tourmaline". Journal of Far East University 27(4): 420-432.

Choi, Y. H., Bulliard, X., Benayad, A., Leterrier, Y., Månson, J. A., Lee, K. H. and Kim, J. (2010) "Design and fabrication of compositionally graded inorganic oxide thin films: Mechanical, optical and permeation characteristics." Acta Materialia, 58(19), 64956503.

Daubinger, P., Kieninger, J., Unmussig, T., Urban, G.A. (2014) "Electrochemical characteristics of nanostructured platinum electrodes - a cyclic voltammetry study", Physical Chemistry Chemical Physics, 16: 8392-8399.

Draper, J.W. (1861). A Textbook on chemistry. New York: Harper and Brothers. p. 93.

Erhart, J., Kittinger, E., Prívratská, J. (2010). "Fundamentals of Piezoelectric Sensorics: Mechanical, Dielectric, and Thermodynamical Properties of Piezoelectric Materials." Springer. p. 4.

Fuchs, Y., Lagache, M., \& Linares, J. (1998). "Fe-tourmaline synthesis under different T and fO2 conditions". American Mineralogist, 83, 525.

Han, L. J., \& Liang, J. S. (2009). "Mechanism of far infrared emission from mineral tourmaline fine powders." Adv. Mater. Res., 58, 77-82. DOI: 10.4028/www.scientific.net/AMR.58.77 
Hawthorne, F. C., \& Henry, D. J. (1999). "Classification of the minerals of the tourmaline group." European Journal of Mineralogy, 11(2), 201.

Henry, D.J., Novák ,M., Hawthorne, F.C., Ertl, A., Dutrow, B.L. Uher, P., and Pezzotta, F. (2011). "Nomenclature of the tourmaline-supergroup minerals". American Mineralogist, 96, 895-913.

Hsieh, Y.Y., Lin, J.P., Liu W.C., Lin, C.C., (2007) "Medical applications and the action mechanisms of far-infrared ray". Taiwanese Journal of Applied Radiation and Isotopes 3(3): 333-340. preparation and its effect on phenolic compounds, antioxidant and ACE inhibitory activity". Journal Medicinal Plants Research, 7(17): $1121-1128$

Hsu, Y. C., \& Teng, T. P. (2016). Enhancement of isobutane refrigerator performance by using far-infrared coating. Energy Conversion and Management, 128, 20-27. https://doi.org/10.1016/j.enconman.2016.09.062

Jin, C.W., Ghimeray, A.K., Wang, L., Xu, M.L., Piao, J.P. (2013) "Far infrared assisted kenaf leaf tea preparation and its effect on phenolic compounds, antioxidant and ACE inhibitory activity". Journal Medicinal Plants Research, 7(17): 1121-1128.

Lee, S.C., Jeong, S.M., Kim, S.Y., Park, H.R., Nam, K.C. (2006) "Effect of far-infrared radiation and heat treatment on the antioxidant activity of water extracts from peanut hulls". Food Chemistry, 94(4): 489-493.

Low, J. J., Kreider, M. L., Pulsifer, D. P., Jones, A. S., \& Gilani, T. H. (2008). "Band gap energy in silicon." American Journal of Undergraduate Research, 7(1), 27-32.

Ni, H., Li, L., \& Li, H. H. (2008). "Tourmaline ceramic balls stimulate growth and metabolism of three fermentation microorganisms." World Journal of Microbiology and Biotechnology, 24(5), 725-731. doi: 10.1007/s11274-007-9529-x

Shen, X., Wu, X., Wei, H., \& Du, W. (2015). "Study on Natural Minerals Applying in Developing New Health Textiles." Journal of Minerals and Materials Characterization and Engineering, 03(04), 248-254. doi: 10.4236/jmmce.2015.34027

Song, S. H., \& Kang, M. (2008). "Decomposition of 2-chlorophenol using a tourmalinephotocatalytic system." Journal of Industrial and Engineering Chemistry, 14(6), 785 791. doi: 10.1016/j.jiec.2008.05.002

Spicer, E.M. (2004) "The low-pressure partial melting behaviour of natural boronbearing metapelites from the Mt. Stafford area, central Australia", Contrib Mineral Petrol, 160-179.

Wang, C., Liu, J., Zhang, Z., Wang, B., \& Sun, H. (2012). "Adsorption of Cd(II), Ni(II), and $\mathrm{Zn}(\mathrm{II})$ by tourmaline at acidic conditions: Kinetics, thermodynamics, and mechanisms." Industrial and Engineering Chemistry Research, 51(11), 4397-4406. https://doi.org/10.1021/ie2023096

Wang, C. P., Wu, J. Z., Sun, H. W., Wang, T., Liu, H. B., \& Chang, Y. (2011). Adsorption of Pb (II) ion from aqueous solutions by tourmaline as a novel adsorbent. Industrial \& Engineering Chemistry Research, 50(14), 8515-8523.

Wang, L., \& Li, Y. "The Function and Health Care of Negative Ion Fibers and Textiles." 
Wang, M., Gong, B., Yao, X., Wang, Y. and Lamb, R. N. (2006) "Preparation and microstructure properties of Al-doped $\mathrm{TiO} 2-\mathrm{SiO} 2$ gel-glass film." Thin Solid Films, 515(4), 2055-2058.

Xia, M. S., Hu, C. H., \& Zhang, H. M. (2006). "Effects of tourmaline addition on the dehydrogenase activity of Rhodopseudomonas palustris." Process Biochemistry, 41(1), 221-225. https://doi.org/10.1016/j.procbio.2005.05.012 